\section{No payroll disasters}

With Wagemate, you get peace of mind that whatever the world throws your way, your team will be paid correctly.

Wagemate will manage every element of your practice's payroll. Its dedicated team is committed to good relationships, including many happy dental clients.

Wagemate can cope with any crisis - its own disaster recovery system is tried-and-tested and was shortlisted for an award in 2020.

Outsource payroll and you can get on with growing your business, delivering quality patient services and creating a great place to work. Don't leave payroll to chance, call Wagemate today.

To better manage your payroll, contact payroll specialists Wagemate today, tel: 03330102102 or email info@ wagemate.com.

\section{Shield your scope from contamination}

Take advantage of the Nuview ScopeShield and Scope-Cone to protect your dental microscopes from contamination. These innovative PPE solutions have been developed in conjunction with leading dental professionals to shield against spray and droplets generated during microscopically assisted dental procedures.

Available in packs of five, the Nuview Scope-Shield seals the gaps at the binocular/shield interface, whilst the Scope-Cone protects the microscope head, with its conical design enabling easy access to the microscope's handles during operation.

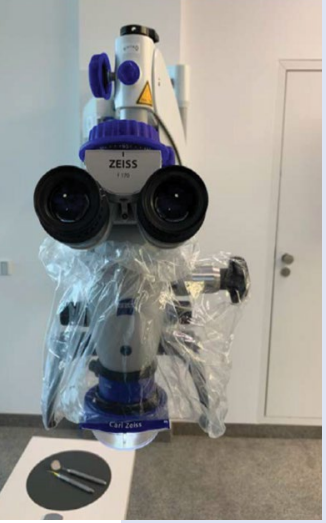

Don't let the risk of cross-infection keep you from utilising your microscope - protect your investment with the Nuview ScopeShield and Scope-Cone. Call now to order.

For more information call Nuview on 01453 872266, emailinfo@ nuview-ltd.com, or visit www.nuview.co.uk.

\section{Encouraging forward motion}

With the UK beginning to look ahead to a brighter and less restricted future, Rodericks Dental is also looking to pick up some forward motion for its professionals. Having always been dedicated to supporting and actively facilitating education and training for individuals, this is the perfect time for all members of its dental teams to refocus on their career development.

Rodericks Dental offers a myriad of in-house CPD and training courses, as well as access to discounted programmes from external courses to help its professionals broaden their skills. There are also clinical advisors available to provide advice and guidance to clinicians still deciding on their next steps, and an extensive network of highly experienced professionals to turn to.
If you're ready for a fresh start and a renewed focus on your career advancement, Rodericks Dental could help you along your way.

For more information on the career opportunities available at Rodericks, visit www.rodericksdentalcareers.co.uk, or contact Ashley Lillyman at recruitment@ rodericksdental.co.uk or on 01604970988 (option 1).

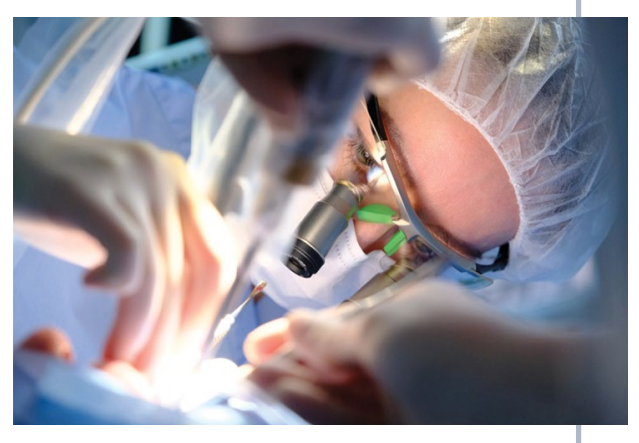

\section{Highly accurate concentricity}

Many conventional surgical handpieces do not adequately clutch Zygomatic dental implant burs. The SZ-75 contra-angle handpiece from W\&H offers a solution.

Developed in collaboration with leading Zygoma implant dentists, the SZ-75 is the world's only 20:1 handpiece with a contra-angle chucking system that holds the bur securely in place to ensure highly accurate concentricity during application. This facilitates safe and effective implant surgery and placement in the zygomatic bone.

With an external spray channel for efficient cooling of the surgical area, the SZ-75 is also ergonomically designed to minimise the risk

\section{For your endodontic referrals}

EndoCare's philosophy is ensuring that every patient gets the help they need, regardless of the complexity of the case.

With decades of experience behind them, the team are all trained to perform only the most up-to-date endodontic treatments and techniques, meaning that they can offer patients practically painfree treatment and solve even the most complex cases. of strain and fatigue, and ensure maximum access to the treatment site.

Order now to optimise your Zygomatic implant workflow.

To find out more visit www.wh.com/ en_uk, call 01727874990 or email office.uk@ wh.com.

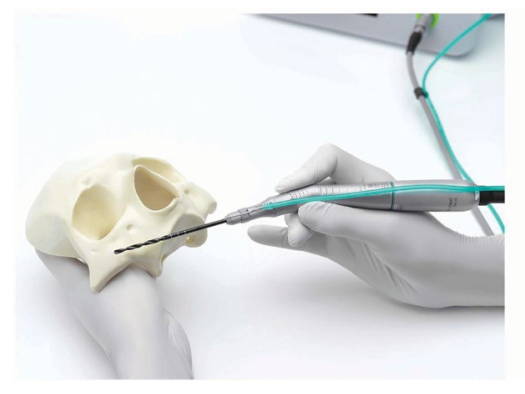

When you refer to EndoCare you can rest assured that they will return your patients to your care with comprehensive details of the treatment they have received and EndoCare's suggested next steps.

Get a helping hand and give your patients the specialist care they need by contacting EndoCare today.

For further information call EndoCare on 02072240999 or visit www.endocare. co.uk. 